\title{
Energy and exergy analysis of a flat plate collector using collector test equations
}

\author{
Adina-Teodora Gheorghian ${ }^{1, *}$, Tudor Prisecaru ${ }^{1}$, and Mihaela Cristina Ciobanu ${ }^{1}$ \\ 1 "Politehnica" University of Bucharest, Department of Engineering Thermodynamics, 313 Splaiul \\ Independentei, 060042, Bucharest, Romania
}

- Abstract. This paper presents the energetic and exergetic analysis of a widely used flat plate collector based on the collector testing equations. The evaluation of the performances of the collector is done under the climatic conditions corresponding to a typical meteorological year in Constanta, Romania. Using a dimensionless-geometric optimization criterion, the climatic conditions for which the energy efficiency and exergetic efficiency have the maximum values are determined. The optimal weather conditions for the collector's operation are: the solar irradiation of $916 \mathrm{~W} / \mathrm{m}^{2}$ and the air temperature of $15.4{ }^{\circ} \mathrm{C}$; under these conditions, the energy and exergy efficiencies of the collector are $57 \%$ and $4.8 \%$, respectively.

\section{Introduction}

Solar collectors are usually investigated based on energy analysis (the first law of thermodynamics). Unfortunately, this analysis does not take into account the degradation of the energy quality that takes place in the process of heating the working fluid [1]. For this, an exergetic analysis (the second law of thermodynamics) should be performed. Exergy analysis is useful for identification of thermodynamic imperfections and for the design improvement of solar systems [2].

In recent years, several papers have been published regarding the thermo-economic modelling and optimization of flat plate collectors (FPC) using energy and exergy analyses.

A procedure for designing and optimizing a FPC based on exergetic analysis is described in the paper [3]. The obtained results show that the energy efficiency increases with the increase of the operating parameters. Exergetic efficiency increases with increasing solar irradiation and decreases rapidly as air temperature and wind speed increase. The exergetic efficiency increases with the inlet fluid temperature until the temperature reaches approximately $315 \mathrm{~K}$, after which it rapidly decreases.

The paper [4] studies the effect of the design parameters on the performance of a FPC based on a theoretical energy and exergy efficiency model. The results of the study showed that the overall performance of the manifold improves when the fluid inlet temperature is 40 degrees higher than the ambient temperature and the mass flow rate is low.

Optimization through maximizing energy efficiency and minimizing the annual cost of a solar heater using flat plate collectors is presented in [5]. To solve the multi objective

* Corresponding author: adina gheorghian@yahoo.com 
optimization problem, the particle swarm optimization (PSO) algorithm is used. The obtained results showed that the highest efficiency and the lowest annual cost are obtained for a lower heat transfer rate.

The paper [6] performs a comprehensive analysis of the energetic, exergetic and financial performances of a flat plate collector and heat pipes located in Fez, Morocco. The mathematical model of the solar collector has been implemented in Matlab based on the coupled heat transfer equations. Using hourly and monthly performance indices, the authors study the effect of the weather, operating and design parameters on the performance collector's. It was found that the best combinations of these parameters are: the temperature of $12.18^{\circ} \mathrm{C}$, the wind speed of $1.5 \mathrm{~m} / \mathrm{s}$, the solar irradiation of $986.93 \mathrm{~W} / \mathrm{m}^{2}$, the fluid's inlet temperature of $45^{\circ} \mathrm{C}$, the mass flow of $0.036 \mathrm{~kg} / \mathrm{s}$ and 13 heat pipes. For this combination, the performance of the collector is optimum (the thermal efficiency is $54.01 \%$, the exergy efficiency is $6.70 \%$ and the overall cost is $771.5 \$$ ).

The energy efficiency analysis of two planar solar collectors based on the collector testing equations and on a theoretical model is presented in paper [7]. The authors point out that the thermal efficiency increases with the mass flow rate, especially at high average temperature values of the working fluid.

The paper [8] presents the exergetic and economic analysis of a FPC that uses riser tubes with two different heat transfer enhancers (a rod and a tube). It has been found experimentally that the rod heat transfer enhancer provides a relatively higher exergy efficiency than the tube heat transfer enhancer. The maximum exergetic efficiency is $11.3 \%$ for the rod and $10.9 \%$ for the tube, compared to only $8.3 \%$ for the rising tube (plane, without enhancer).

This study presents the energetic and exergetic analysis of a FPC based on the collector testing equations. The evaluation of the performances of the collector is carried out under the climatic conditions corresponding to a typical meteorological year in Constanta, Romania. Using a dimensionless-geometric optimization criterion, the climatic conditions for which the energy efficiency and exergetic efficiency have maximum values are determined.

\section{Methods}

\subsection{Solar collector}

The studied solar collector is a FPC type, which has good performances and is mostly often used for domestic hot water preparation.

The technical characteristics of a good quality FPC, frequently met on the local market, are provided in Table 1.

Table 1. Main characteristics of the studied flat plate solar collector

\begin{tabular}{|l|l|l|}
\hline \multicolumn{1}{|c|}{ Characteristic } & UM & \multicolumn{1}{c|}{ Value } \\
\hline Dimensions (Length $\mathrm{x}$ Width $\mathrm{x}$ Height) & $\mathrm{mm}$ & $1970 \times 970 \times 86$ \\
\hline Gross area, $\mathrm{A}_{\mathrm{G}}$ & $\mathrm{m}^{2}$ & 1.91 \\
\hline Aperture area, $\mathrm{A}_{\mathrm{A}}$ & $\mathrm{m}^{2}$ & 1.73 \\
\hline Absorber & - & Cooper with blue selective coating \\
\hline Cover & - & Tempered, low iron prismatic glass $4 \mathrm{~mm}$ \\
\hline Insulation (rock wool) & - & back $: 40 \mathrm{~mm}$, edge $: 20 \mathrm{~mm}$ glass \\
\hline Weight & $\mathrm{kg}$ & 41 \\
\hline
\end{tabular}


The performance parameters, determined by the steady state method, mentioned in the test certificate of the collector, are shown in Table 2.

Table 2. Performance parameters (related to gross area) of the studied FPC

\begin{tabular}{|l|l|l|}
\hline \multicolumn{1}{|c|}{ Parameter } & \multicolumn{1}{c|}{ UM } & \multicolumn{1}{c|}{ Value } \\
\hline Peak collector efficiency, $\eta_{0, \mathrm{~b}}$ & - & 0.672 \\
\hline Heat loss coefficient, $\mathrm{a}_{1}$ & $\mathrm{~W} /\left(\mathrm{m}^{2} \times \mathrm{K}\right)$ & 0.310 \\
\hline Temperature dependence of heat loss coefficient, $\mathrm{a}_{2}$ & $\mathrm{~W} /\left(\mathrm{m}^{2} \times \mathrm{K}^{2}\right)$ & 0.014 \\
\hline $\begin{array}{l}\text { Incidence angle modifier for beam irradiance, } \mathrm{K}_{\mathrm{b}}(\theta) \\
\text { for } \theta=[10203040506070 \text { 80] degree }\end{array}$ & - & {$\left[\begin{array}{lll}1.00 & 0.990 .970 .93 \\
& & 0.880 .780 .580 .00\end{array}\right]$} \\
\hline Incidence angle modifier for diffuse irradiance, $\mathrm{K}_{\mathrm{d}}$ & - & 0.82 \\
\hline Flow rate for testing & $\mathrm{kg} /\left(\mathrm{s}^{\circ} \times \mathrm{m}^{2}\right)$ & 0.02 \\
\hline Heat transfer fluid & - & water-glycol \\
\hline
\end{tabular}

These performance parameters were used as input data for the mathematical model described below.

\subsection{Location and weather data}

The location chosen for this study was the city of Constanta $\left(44.177^{\circ} \mathrm{N}, 28.633^{\circ} \mathrm{E}\right.$, III 9 climate region), on the Black Sea coast.

A set of hourly meteorological data corresponding to a Typical Meteorological Year (TMY) for this location was retrieved using Photovoltaic Geographical Information System (PVGIS) TMY tool [9]. The annual range used to define TMY was 2007-2016.

The meteorological parameters used as input data in the mathematical model were: time, $t[\mathrm{~h}]$, ambient air temperature, $T_{\mathrm{a}}\left[{ }^{\circ} \mathrm{C}\right]$, solar irradiance on a horizontal surface, $G_{\text {horiz }}$ $\left[\mathrm{W} / \mathrm{m}^{2}\right]$ and solar irradiance on a surface always normal to the Sun, $G_{\mathrm{bn}}\left[\mathrm{W} / \mathrm{m}^{2}\right]$.

\subsection{Mathematical model}

The useful power extracted from the solar collector according to ISO 9806, valid for steadstate testing, is:

$$
\dot{Q}_{\mathrm{u}}=\mathrm{A}_{\mathrm{G}}\left[\eta_{0, \mathrm{~b}} K_{\mathrm{b}}(\theta) G_{\mathrm{b}}+\eta_{0, \mathrm{~b}} K_{\mathrm{d}} G_{\mathrm{d}}-\mathrm{a}_{1}\left(T_{\mathrm{m}}-T_{\mathrm{a}}\right)-\mathrm{a}_{2}\left(T_{\mathrm{m}}-T_{\mathrm{a}}\right)^{2}\right],
$$

where $\mathrm{A}_{\mathrm{G}}\left[\mathrm{m}^{2}\right]$ is the collector's gross area, $\eta_{0, \mathrm{~b}}$ - peak collector's efficiency, $K_{\mathrm{b}}(\theta)$ - the incidence angle modifier for beam solar irradiance, $G_{\mathrm{b}}\left[\mathrm{W} / \mathrm{m}^{2}\right]$ - beam solar irradiance, $K_{\mathrm{d}}-$ the incidence angle modifier for diffuse solar irradiance, $G_{\mathrm{d}}\left[\mathrm{W} / \mathrm{m}^{2}\right]-$ diffuse solar irradiance, $a_{1}\left[\mathrm{~W} / \mathrm{m}^{2} / \mathrm{K}\right]$ - the heat loss coefficient, $\mathrm{a}_{2}\left[\mathrm{~W} / \mathrm{m}^{2} / \mathrm{K}^{2}\right]-$ temperature dependence on the heat loss coefficient, $T_{\mathrm{m}}\left[{ }^{\circ} \mathrm{C}\right]$ - mean temperature of heat transfer fluid, $T_{\mathrm{a}}\left[{ }^{\circ} \mathrm{C}\right]-$ ambient air temperature. Details of computing beam and diffuse solar irradiance can be found in reference [10]. The incidence angle modifier is computed by linear interpolation using the input data.

The annual useful energy per square meter of the solar collector is obtained by summing the heat produced every hour of a year:

$$
\frac{Q}{\mathrm{~A}_{\mathrm{G}}}=\sum_{t=0}^{t=8760} \frac{\dot{\mathrm{Q}}_{\mathrm{u}}}{\mathrm{A}_{\mathrm{G}}} \cdot t
$$


The thermal efficiency of the collector, which is defined as the ratio of the useful gain over one hour to the incident solar energy over the same time period is:

$$
\eta=\frac{\dot{Q}_{\mathrm{u}}}{\dot{Q}_{\mathrm{S}}}=\frac{\dot{m} \mathrm{C}_{\mathrm{p}}\left(T_{\mathrm{out}}-T_{\mathrm{in}}\right)}{A_{\mathrm{G}} \cdot G_{\mathrm{T}}},
$$

where $T_{\text {out }}\left[{ }^{\circ} \mathrm{C}\right]$ is the working fluid's outlet temperature, $T_{\text {in }}\left[{ }^{\circ} \mathrm{C}\right]$ is the working fluid's inlet temperature, $G_{\mathrm{T}}\left[\mathrm{W} / \mathrm{m}^{2}\right]$ - global solar irradiation on the tilted surface, $\left[\mathrm{kg} / \mathrm{s} / \mathrm{m}^{2}\right]-$ the mass $\dot{m}$ flow rate of the working fluid per $\mathrm{m}^{2}$ of collector, $\mathrm{C}_{\mathrm{p}}[\mathrm{J} / \mathrm{kg} / \mathrm{K}]-$ the specific heat of the fluid, $[\mathrm{W}]-$ the power $\dot{Q}_{\mathrm{S}}$ received from the Sun.

The exergy efficiency of the collector is the ratio of the useful exergy $E x_{\mathrm{u}}$ over the absorbed exergy $E x_{\mathrm{S}}[2]$ :

$$
\eta_{\mathrm{ex}}=\frac{\dot{E} x_{\mathrm{u}}}{\dot{E} x_{\mathrm{S}}}=\frac{\dot{m} \mathrm{C}_{\mathrm{p}}\left[\left(T_{\text {out }}-T_{\mathrm{in}}\right)-T_{\mathrm{a}} \ln \left(\frac{T_{\text {out }}}{T_{\text {in }}}\right)\right]}{\mathrm{A}_{\mathrm{G}} \cdot G_{\mathrm{T}}\left[1-\frac{4}{3}\left(\frac{T_{\mathrm{a}}}{T_{\mathrm{S}}}\right)+\frac{1}{3}\left(\frac{T_{\mathrm{a}}}{T_{\mathrm{S}}}\right)^{4}\right]}
$$

where $T_{\mathrm{S}}=6273\left[{ }^{\circ} \mathrm{C}\right]$ is the Sun's temperature.

The geometric criterion used for multi-objective optimization evaluates the distance between each objective function point and the ideal point using the expression [11]:

$$
C=\sqrt{\left(\frac{\eta_{\mathrm{ex}, \text { max }}-\eta_{\mathrm{ex}}}{\eta_{\mathrm{ex}, \text { max }}-\eta_{\mathrm{ex}, \text { min }}}\right)^{2}+\left(\frac{\eta_{\max }-\eta}{\eta_{\max }-\eta_{\min }}\right)^{2}},
$$

where $\eta_{\max }, \eta_{\min }$ are the thermal efficiency's maximum and minimum values during a year and $\eta_{\text {ex,max }}, \eta_{\text {ex,min }}$ - the exergy efficiency's maximum and minimum values.

\section{Results and discussions}

\subsection{Meteorological data}

In order to characterize the weather conditions in Constanta, air temperature and global irradiation on a horizontal surface and on a tilted surface are plotted, hourly, for the recommended average day of each month of the year [12].

The air temperature values $2 \mathrm{~m}$ above the ground in Constanta during the average day of each month of the year are presented in Fig. 1. 


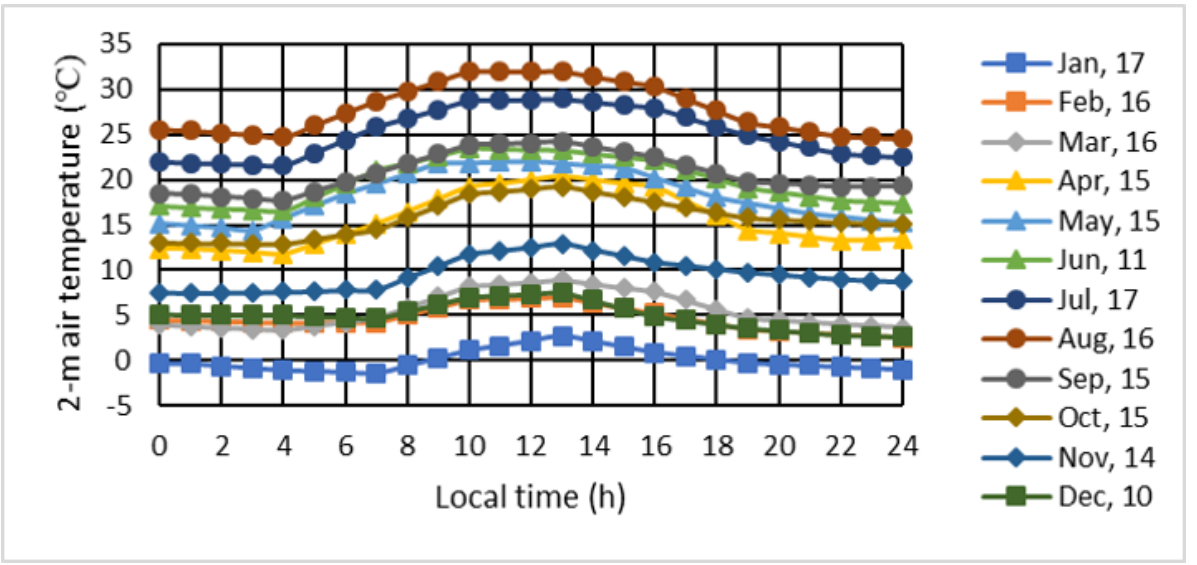

Fig. 1. Air temperature as a function of the hour of the day.

As one may see in Figure 1, the temperature difference between day and night is on average $6{ }^{\circ} \mathrm{C}$. The maximum air temperature is recorded in August 16 and it is about $32{ }^{\circ} \mathrm{C}$, while the minimum temperature is $-2{ }^{\circ} \mathrm{C}$ in January 17 . The air temperature reaches the maximum at noon, between 12-14 hours, while the minimum value is recorded at dawn, between 04-07 hours.

Figs. 2 and 3 show the hourly variation of global solar irradiation on a horizontal surface and on a $30^{\circ}$ tilted surface, respectively on recommended average days. Solar irradiation has the highest values during summer: in May, June, and July. Maximum solar irradiation occurs at noon on June $11\left(940 \mathrm{~W} / \mathrm{m}^{2}\right.$ on a horizontal surface) and on May 15 $\left(990 \mathrm{~W} / \mathrm{m}^{2}\right.$ on a $30^{\circ}$ tilted surface $)$.

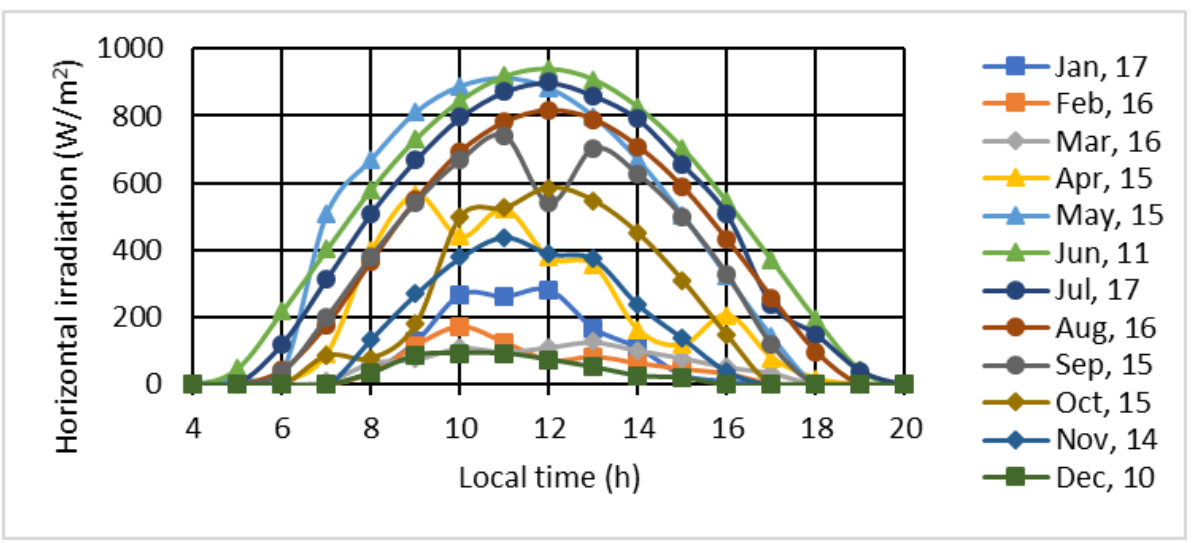

Fig. 2. Overall solar irradiation on a horizontal surface as a function of the hour of the day. 


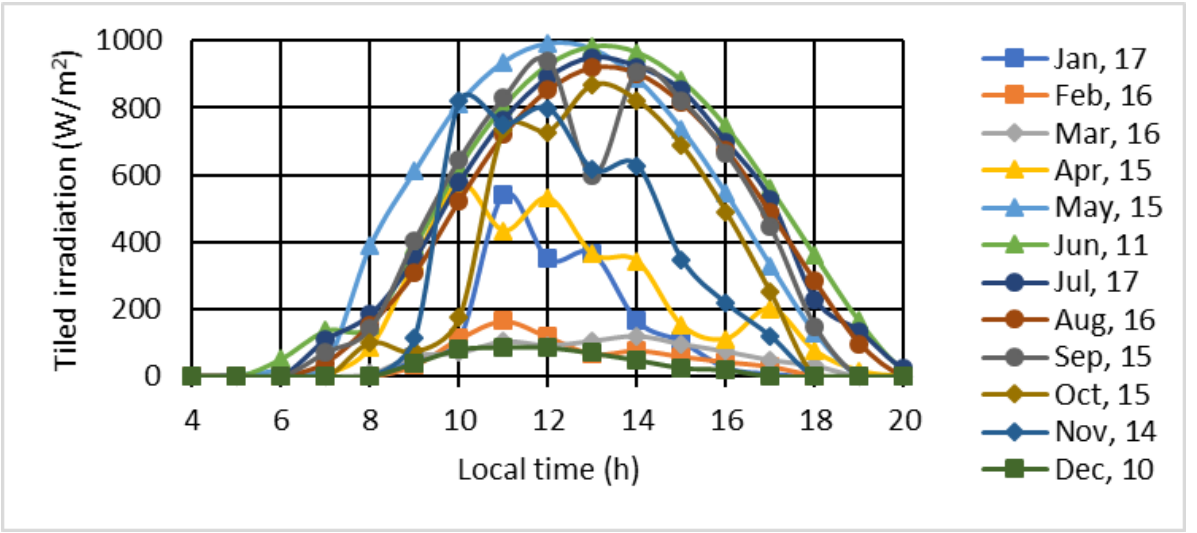

Fig. 3. Global solar irradiation on a $30^{\circ}$ tilted surface as a function of the hour of the day.

The difference between the irradiation on a horizontal and a tilted surface increases considerably during the autumn months. On 14th of November at 11 o'clock, the maximum irradiation on a horizontal surface is $440 \mathrm{~W} / \mathrm{m}^{2}$ and at 12 o'clock on the same day, the maximum irradiation on a $30^{\circ}$ tilted surface is $800 \mathrm{~W} / \mathrm{m}^{2}$. In the winter months, solar irradiation is low, the maximum value does not exceed $200 \mathrm{~W} / \mathrm{m}^{2}$.

The variation of the water temperature at the exit of the collector in the weather conditions described above is graphically represented in Fig. 4.

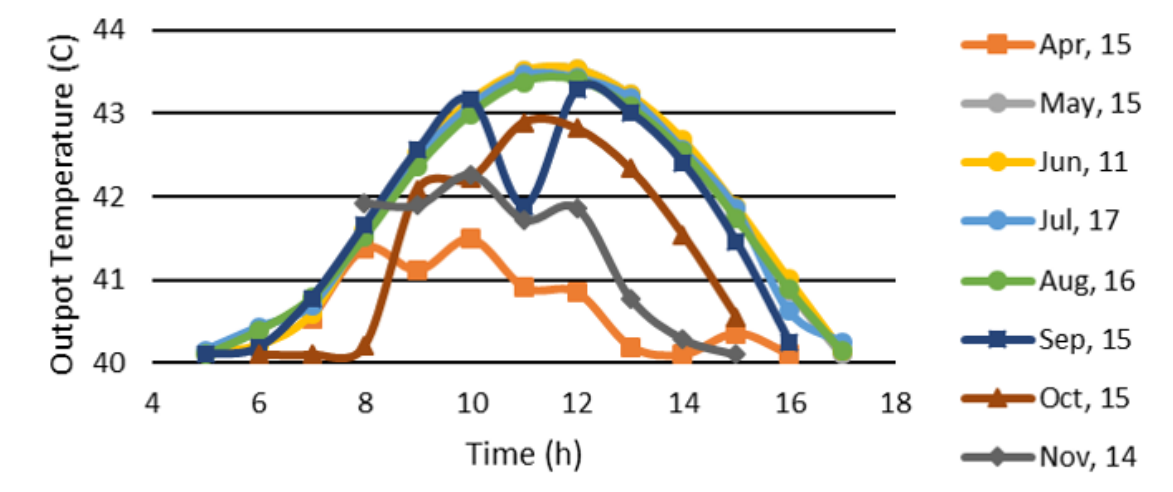

Fig. 4. Water temperature exiting the collector as a function of the hour of the day $\left(\theta_{\mathrm{m}}=40^{\circ}\right)$.

The calculations were performed for a mass flow of $0.02 \mathrm{~kg} / \mathrm{s} / \mathrm{m}^{2}$ and an average water temperature (between the inlet and the outlet of the collector) of $40{ }^{\circ} \mathrm{C}$. It can be noticed that the collector can produce hot water with a temperature above $42{ }^{\circ} \mathrm{C}$ from May to October. For the rest of the months of the year it is necessary to use a gas or electric boiler to heat the water up to this level.

The influence of air temperature and solar irradiation on the energy and exergy efficiencies of the FPC is investigated below. During this investigation, the mass flow and the average water temperature were kept constant, at the values mentioned above.

\subsection{Air temperature's effect}

In order to analyze the influence of the air temperature on the efficiency of the FPC, an annual simulation of the collector's operation was performed. The air temperature was 
corresponding to the typical meteorological year (TMY) previously mentioned and the solar irradiation was set to a constant value of $500 \mathrm{~W} / \mathrm{m}^{2}$.

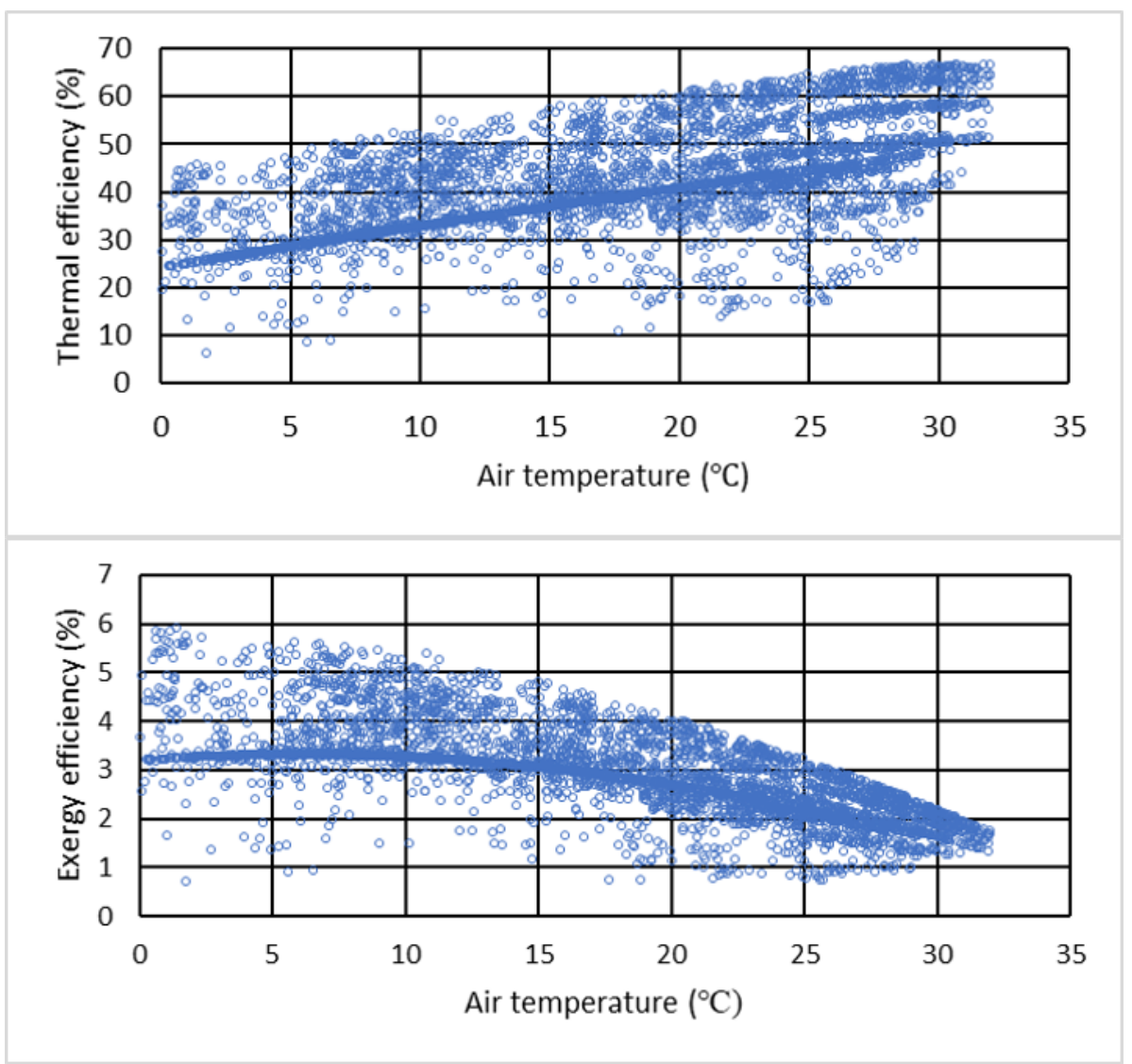

Fig. 5. Air temperature's effect on thermal and exergy efficiencies (solar irradiance $500 \mathrm{~W} / \mathrm{m}^{2}$ ).

As it can be seen from Fig. 5, an increase in the air temperature leads to an almost linear increase in the energy efficiency. For an increase of $10^{\circ} \mathrm{C}$ in air temperature, the efficiency increases by about $10 \%$. This dependence is due to the decrease of the thermal losses of the collector as the air temperature increases.

The air temperature increase determines the decrease of the exergetic efficiency of the collector, initially slower and after reaching the value of $15^{\circ} \mathrm{C}$, more pronounced. This is because the exergy destruction in solar collectors increases with the increase of the air temperature [5].

\subsection{Effect of solar irradiation}

This analysis was done by simulating the operation of the FPC for a whole year, at a constant air temperature of $15{ }^{\circ} \mathrm{C}$ and a solar irradiation corresponding to the typical meteorological year. 


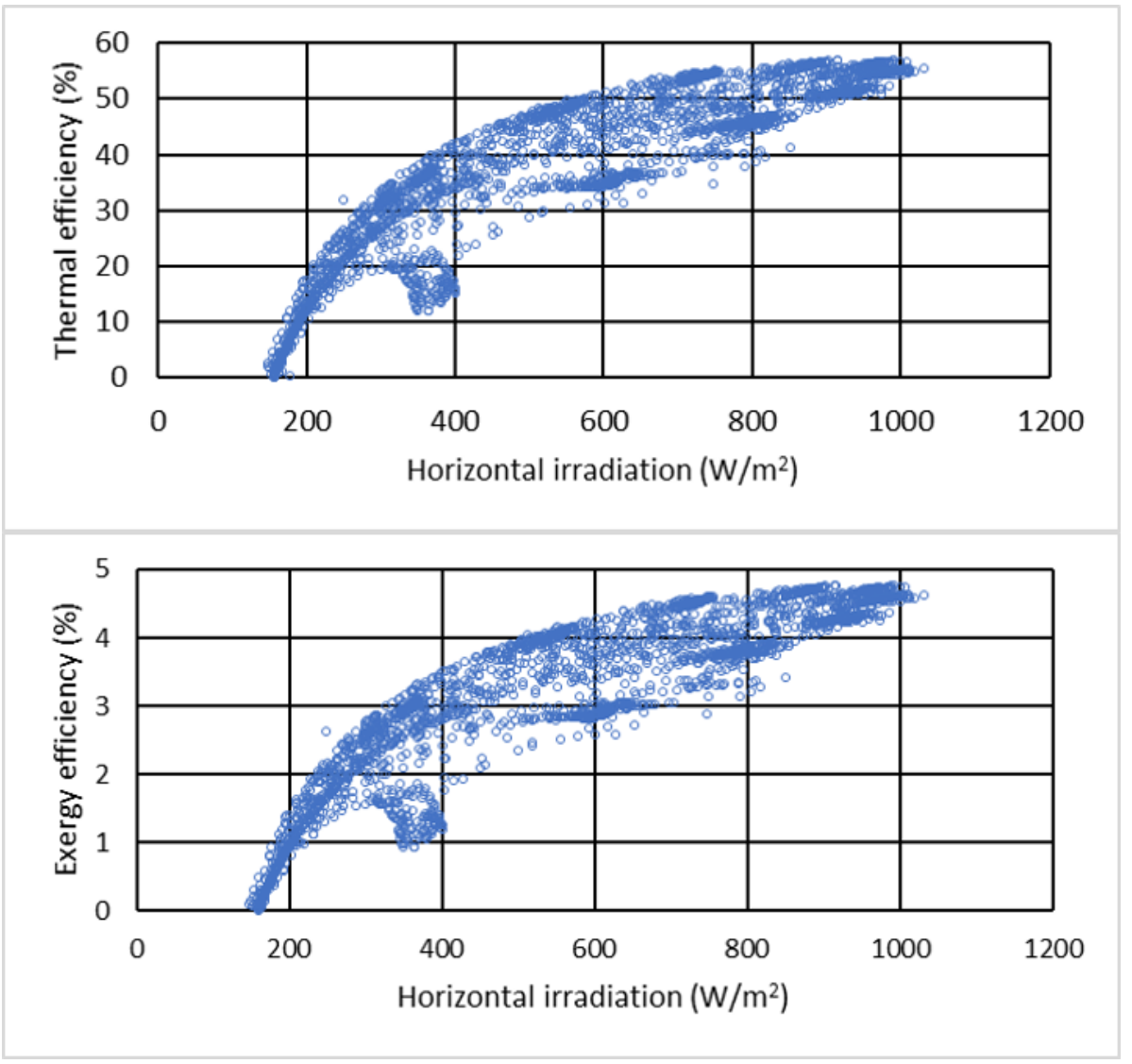

Fig. 6. Solar irradiation's effect on thermal and exergy efficiencies (air temperature $20{ }^{\circ} \mathrm{C}$ ).

The efficiency of the collector for different values of solar irradiation recorded hourly during TMY is graphically represented in Figure 6. Both efficiencies, energetic and exergetic, increase with the increase of solar irradiation, following a similar pattern. The slope of the efficiency decreases continuously as the solar irradiation increases, at the beginning faster and after reaching the value of $350 \mathrm{~W} / \mathrm{m}^{2}$ slower. The maximum limits of the FPC's efficiency are reached at a solar irradiation of $1000 \mathrm{~W}$, when the energy efficiency is $55 \%$ and the exergetic one is $4.5 \%$.

The monthly energy provided by the FPC at air temperatures and solar irradiations corresponding to the typical meteorological year mentioned are studied below. The simulations were performed for a mass flow rate of $0.02 \mathrm{~kg} / \mathrm{s} / \mathrm{m}^{2}$ and an average water temperature of $40^{\circ} \mathrm{C}$.

\subsection{Energy and exergy produced by the FPC}

The values of the useful energy and exergy produced by the FPC were calculated for each month of the year by numerical integration. The results are graphically presented in Fig. 7. 


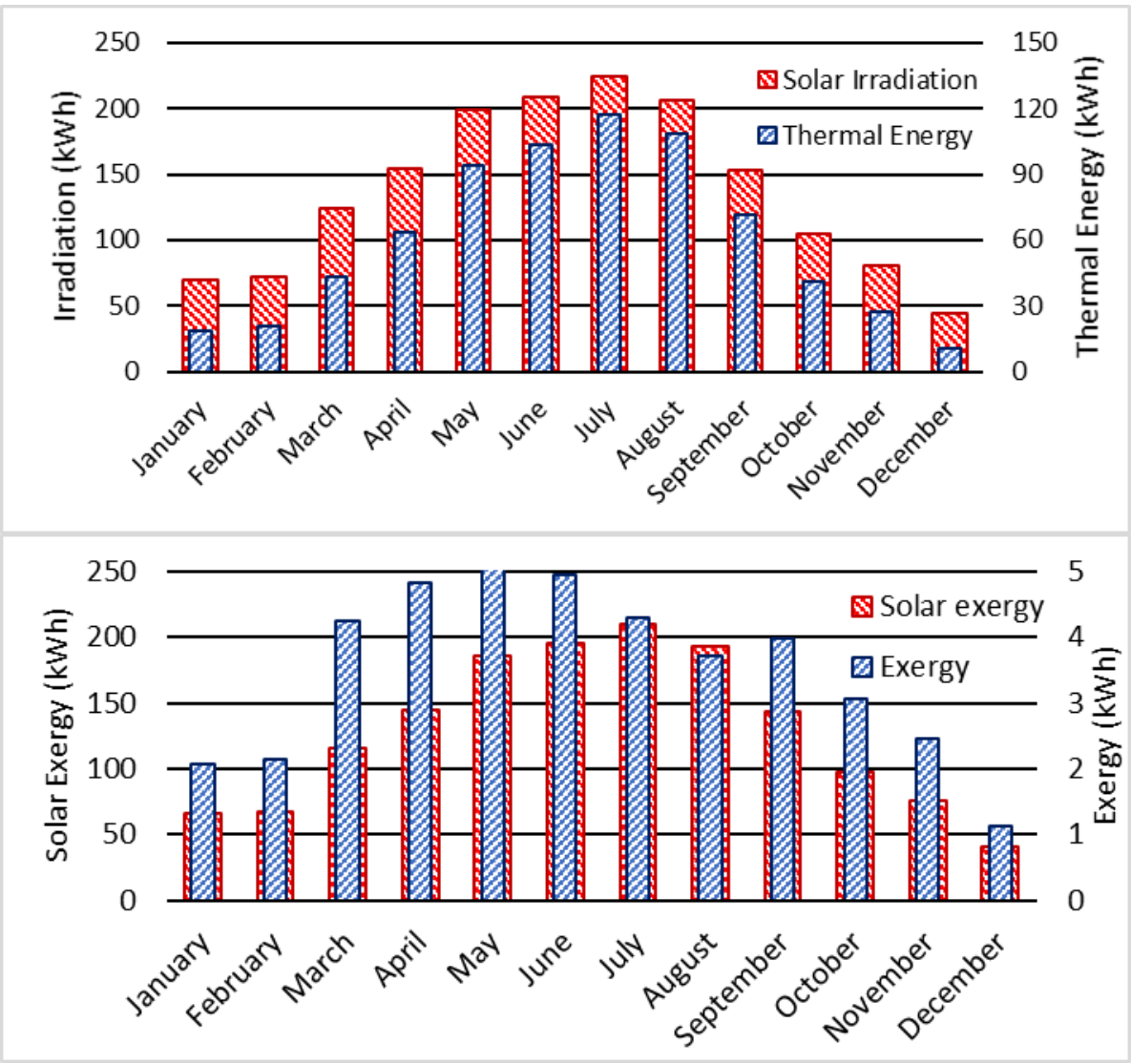

Fig. 7. Energy and exergy values produced by the FPC as a function of the month of the year.

The sunniest month of the year is July, when the solar irradiation reaches $230 \mathrm{kWh}$ and the useful energy exceeds $120 \mathrm{kWh}$. Solar exergy is maximum in July, having a value of $210 \mathrm{kWh}$, but the output exergy is maximum in May $(5 \mathrm{kWh})$, when the air temperature is lower than it is in July.

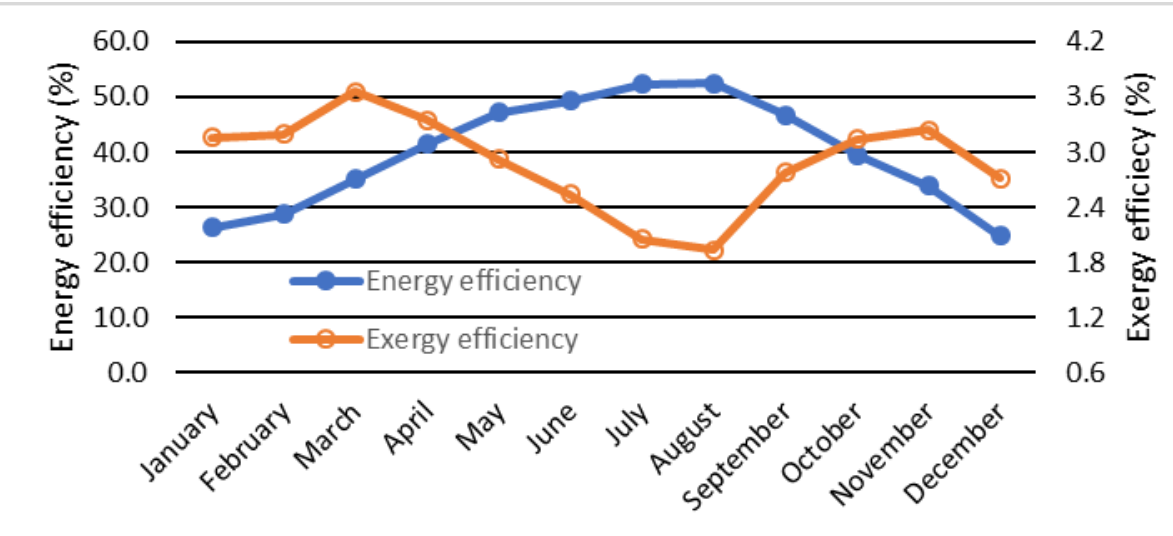

Fig. 8. Energy and exergy efficiencies of the FPC as a function of the month of the year. 
The monthly energy and energy efficiency of the collector were computed based on the data presented in Fig. 7 (see Fig. 8). It was found that the energy efficiency has a maximum value during the summer months (over 50\%), while the exergetic efficiency reaches maximum values in the spring-autumn months $(3.6 \%)$, when the solar exergy is still significant (over $100 \mathrm{kWh}$ ) and the air temperature is not very high.

During winter months (December-February) the energy efficiency of the collector is around $25 \%$ and the energy efficiency is $3 \%$.

The influence of the average temperature of the water on the efficiency of the collector is studied below.

\subsection{Effect of mean temperature}

The results of the simulation of the FPC operating under the meteorological conditions defined by TMY, for a constant mass flow of $0.02 \mathrm{~kg} / \mathrm{s} \mathrm{m}^{2}$ and three average water temperature values are summarized in Table 3.

Table 3. Efficiency at three different mean temperatures of water.

\begin{tabular}{|l|l|l|l|l|l|l|}
\hline \multirow{2}{*}{ Month } & \multicolumn{6}{|c|}{ Mean temperature, ${ }^{\circ}$ C } \\
\cline { 2 - 7 } & \multicolumn{2}{|c|}{30} & \multicolumn{2}{c|}{40} & \multicolumn{2}{c|}{50} \\
\cline { 2 - 7 } & $\eta$ & $\eta_{\mathrm{ex}}$ & $\eta$ & $\eta_{\mathrm{ex}}$ & $\eta$ & $\eta_{\mathrm{ex}}$ \\
\hline January & 32.8 & 2.9 & 26.3 & 3.2 & 20.3 & 3.0 \\
\hline February & 35.1 & 2.8 & 28.8 & 3.2 & 23.4 & 3.3 \\
\hline March & 41.6 & 3.0 & 35.0 & 3.7 & 28.9 & 3.9 \\
\hline April & 48.2 & 2.3 & 41.4 & 3.4 & 35.3 & 3.9 \\
\hline May & 53.4 & 1.6 & 47.1 & 2.9 & 41.4 & 3.9 \\
\hline June & 55.6 & 1.0 & 49.4 & 2.5 & 43.4 & 3.6 \\
\hline July & 58.2 & 0.3 & 52.3 & 2.1 & 46.4 & 3.3 \\
\hline August & 58.7 & 0.2 & 52.6 & 1.9 & 46.7 & 3.2 \\
\hline September & 53.4 & 1.4 & 46.8 & 2.8 & 40.6 & 3.7 \\
\hline October & 46.4 & 2.2 & 39.5 & 3.1 & 33.0 & 3.6 \\
\hline November & 40.8 & 2.6 & 33.9 & 3.2 & 27.5 & 3.5 \\
\hline December & 31.0 & 2.4 & 24.7 & 2.7 & 18.9 & 2.6 \\
\hline
\end{tabular}

One may see that the increase of the working fluid's average temperature leads to the decrease of the energy efficiency. That is because, with the increase of the average temperature, the temperature difference at which the heat transfer takes place is reduced. Thus, the useful heat gained decreases and, consequently, the thermal efficiency decreases.

Also, it is found that the increase of the average temperature leads to the increase of the exergetic efficiency. This is due to the decrease of the exergy losses to the environment with the increase of the average fluid's temperature.

\subsection{Optimal weather conditions}

For finding the appropriate meteorological conditions for which the energetic and exergetic efficiencies are maximum, the geometric criterion (5) was used. 
Fig. 9 shows the variation of the exergetic efficiency according to the energy efficiency calculated hourly, throughout the typical meteorological year.

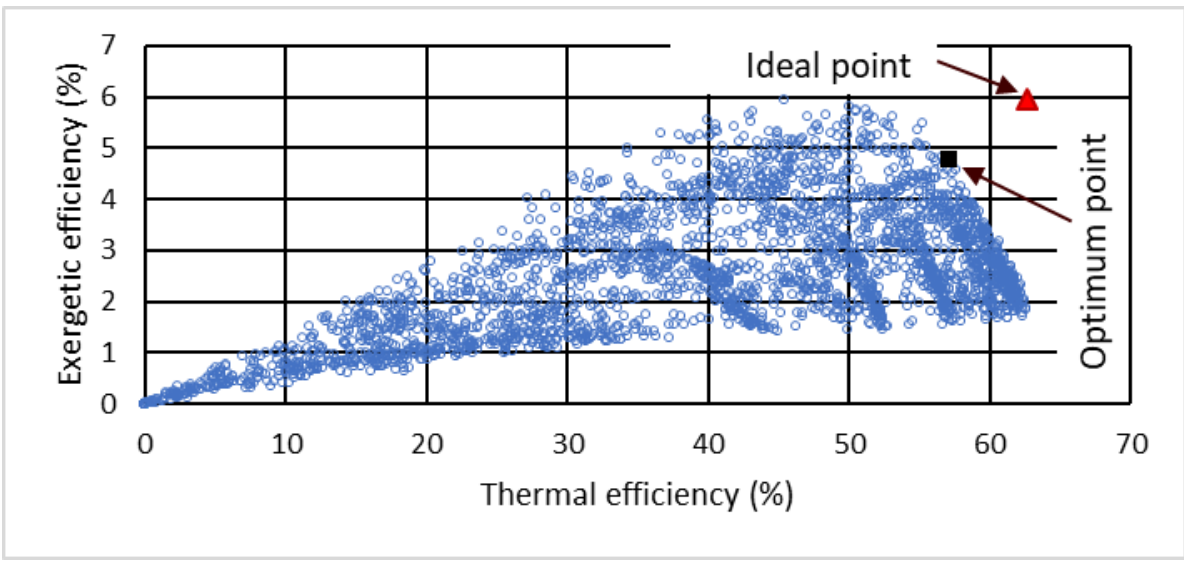

Fig. 9. Exergetic efficiency of the FPC as a function of its thermal efficiency.

The ideal point of coordinates $\left(\eta_{\max }=62 \%, \eta_{\mathrm{ex}, \max }=6 \%\right)$ is represented on the graph by a triangle. The position of the closest point to the ideal point, the so-called optimal point with the coordinates $\left(\eta_{\text {opt }}=57 \%, \eta_{\text {ex,opt }}=4.8 \%\right)$ represented by a square, was found using the geometric criterion. The optimal meteorological conditions corresponding to the optimum point are: the solar irradiation of $916 \mathrm{~W} / \mathrm{m}^{2}$ and the air temperature of $15.4{ }^{\circ} \mathrm{C}$.

\section{Conclusions}

The use of the test equations allows the achievement of the energetic and exergetic analyses of a FPC mounted in a location for which the weather data for a typical meteorological year are known.

Based on the analyses carried out for a good quality FPC, located on the Black Sea coast, in the city of Constanta, the following conclusions can be formulated:

- the increase in the air temperature leads to an almost linear increase of the energy efficiency; at an increase in air temperature of $10{ }^{\circ} \mathrm{C}$, the efficiency increases by about $10 \%$;

- increasing the air temperature causes the collector's exergetic efficiency to decrease, initially slower and after reaching $15^{\circ} \mathrm{C}$, more pronounced;

- energy and exergy efficiencies increase with increasing solar irradiation, initially faster and after the irradiation reaches $350 \mathrm{~W} / \mathrm{m}^{2}$, slower;

- the sunniest month of the year is July, when the solar irradiation reaches $230 \mathrm{kWh}$ and the useful energy exceeds $120 \mathrm{kWh}$; the solar exergy is maximum in July, when it has a value of $210 \mathrm{kWh}$, while the output exergy is maximum in May, having a value of $5 \mathrm{kWh}$;

- energy efficiency is maximum during the summer months (over 50\%), while the exergetic efficiency reaches maximum values in the spring-autumn months $(3.6 \%)$;

- the increase in the working fluid's average temperature leads to the decrease of the energy efficiency and the increase of the exergetic efficiency;

- optimal weather conditions for the collector's operation are: the solar irradiation of $916 \mathrm{~W} / \mathrm{m}^{2}$ and the air temperature of $15.4^{\circ} \mathrm{C}$; under these conditions, the energy and exergy efficiencies of the collector are $57 \%$ and $4.8 \%$, respectively. 
For a more detailed analysis of the performance of a FPC, it would be necessary to use the complete mathematical model, implemented in a high programming language coupled with an hourly weather data set corresponding to a TMY.

Acknowledgments

This paper is a result of the research conducted within the project ME15-18-01, within the national program $\mathrm{GNaC} 2018$ ARUT.

\section{References}

1. S. A. Kalogirou, S. Karellas, K. Braimakis, C. Stanciu, V. Badescu, Exergy analysis of solar thermal collectors and processes, Progress in Energy and Combustion Science, Volume 56, Pages 106-137, (2016)

2. H. Gunerhan, A. Hepbasli, Exergetic modeling and performance evaluation of solar water heating systems for building applications, Energy Build, 39, 509-516, (2007)

3. S. Farahat, F. Sarhaddi, H. Ajam, Exergetic optimization of flat plate solar collectors, Renewable Energy 34, 1169-1174, (2009)

4. F. Jafarkazemi, E. Ahmadifard, Energetic and exergetic evaluation of flat plate solar collectors, Renewable Energy, Volume 56, Pages 55-63, (2013)

5. Z. Hajabdollahi, H. Hajabdollahi, Thermo-economic modeling and multi-objective optimization of solar water heater using flat plate collectors, Solar Energy 155, 191202, (2017)

6. A. Allouhi, M. B. Amine, Effect analysis on energetic, exergetic and financial performance of a flat plate collector with heat pipes, Energy Conversion and Management 195, 274-289, (2019)

7. Z. Chen, S. Furbo, B. Perers, J. Fan, E. Andersen, Efficiencies of flat plate solar collectors at different flow rates, Energy Procedia 30, 65 - 72, (2012)

8. K. Balaji, S. Iniyan, M. V. Swami, Exergy, economic and environmental analysis of forced circulation flat plate solar collector using heat transfer enhancer in riser tube, Journal of Cleaner Production 171, 1118-11 27, (2018)

9. PVGIS Interactive tools TMY, retrieved from https://re.jrc.ec.europa.eu/pvg_tools/en/tools.html\#TMY, February 10, (2020)

10. J.E. Hay, J.A. Davies, Calculations of the solar radiation incident on an inclined surface. In: Hay, J.E., Won, T.K. (Eds.), Proc. of First Canadian Solar Radiation Data Workshop, 59. Ministry of Supply and Services, Canada, (1980)

11. Bellos E., Tzivanidis C., Multi-objectiv optimization of a solar driven trigeneration system. Energy 2018, 149:47-62, (2018)

12. J.A. Duffie, W.A. Beckman, Solar Engineering of Thermal Processes, 4th ed., John Wiley \& Sons, Hoboken, (2013) 